\section{Resumen}

Existen cuatro aspectos donde la visualización de las imágenes e ideas contradictorias y paradójicas sobre la infancia de hoy resulta particularmente clara: la criminalidad, la sexualidad, el trabajo y la educación. En estos se reúnen las más fuertes tensiones morales y se entrecruzan intereses económicos y políticos en una disputa por mantener, transformar y controlar una concepción de infancia y, con ella, a los propios niños y niñas. Estas formas paradójicas de la infancia que coexisten simultáneamente son el objeto de atención y producción de un conjunto de disciplinas, instituciones y prácticas, que forman parte de lo que se ha denominado campo discursivo sobre la infancia.

En medio de ese campo discursivo emerge la infancia-quimera, que nos sorprende, que nos inspira ternura, nos provoca sentimientos y deseos de protegerla y abrigarla, al tiempo que puede generarnos temores, miedos y hasta rencores; en fin, esa infancia que se nos revela como acontecimiento, como novedad, como impredecible y para cuyo encuentro es necesario dejar atrás muchos de nuestros saberes y de nuestras prácticas para no tratar de re-conocerla, apropiarla, someterla y domesticarla, y si para escucharla, para recibirla en su aproximación inquietante, sugestiva y sorpresiva, en su aproximación como por venir, como novedad.

\section{Palabras clave:}

Infancia, campo discursivo, historia de la infancia.

\section{Abstract}

Exist four aspects where the visualization of the images and contradictory and paradoxical ideas on today's childhood, they are particularly clear: the crime rate, the sexuality, the work and the education. In them, they meet the strongest moral tensions and they intersect it interests economic and political in a dispute to maintain, to transform and to control a childhood conception and with her to the own children and girls. These paradoxical forms of the childhood that coexist simultaneously are the object of attention and production of a group of disciplines, institutions and practical that make part of what has been denominated discursive field on the childhood.

Amid of that discursive field, the childhood-chimera that we are surprised that inspires us fondness emerges it provokes us feelings and desires of to protect it and to shelter it, at the time it can generate us fears, fears and until bitterness; in short that childhood that we are revealed as event, as novelty, as unpredictable and it stops whose encounter is necessary to leave behind, much of our knowledge and of our practices for not being about re-cognize, to adapt it, to subject it and to tame it; and if to listen to it, to receive it in their disturbing, suggestive and surprising approach, in their approach like to come, as novelty.

\section{Keywords:}

Childhood, discursive field, childhood history. 


\title{
La infancia como problema o el problema de la in-fancia ${ }^{1}$
}

\section{Carlos Ernesto Noguera Ramírez² \\ Dora Lilia Marín Díaz ${ }^{3}$}

\begin{abstract}
Esos locos bajitos, que se incorporan, con los ojos abiertos de par en par, sin respeto al horario ni a las costumbres y a los que por su bien, dicen que hay que domesticar...

Joan Manuel Serrat

Una imagen del otro es una contradicción. Pero tal vez nos quede una imagen del encuentro con el otro. En ese sentido, no sería una imagen de la infancia, pero sí una imagen a partir del encuentro con la infancia.
\end{abstract}

Jorge Larrosa

Esos locos bajitos que no conocen de nuestras normas, de nuestros dioses ni de nuestra lengua; esos seres pequeños para quienes construimos instituciones y adecuamos prácticas para acogerlos, cuidarlos, amarlos, conocerlos, educarlos, civilizarlos, en fin, domesticarlos; esos sujetos infantiles cuyas necesidades, desarrollos psicológicos y biológicos, modos de pensar y sentir, ritmos de crecimiento y aprendizaje aparecen descritos y prescritos en un sinnúmero de libros, revistas, programas de televisión, páginas de Internet, planes y proyectos; esos locos bajitos, a pesar de toda esta parafernalia, aún pueden sorprendernos con sus respuestas, con sus acciones, con sus expresiones, con su novedad.

Tenemos hoy, como nunca antes, una enorme cantidad de información disponible y un elevado número de especialistas que nos dicen, sugieren y explican las

\footnotetext{
${ }^{1}$ Texto recibido el 1 de junio de 2007, evaluado en 24 y 29 de agosto de 2007 y arbitrado el 10 de septiembre de 2007.

2 Profesor Asociado Universidad Pedagógica Nacional de Colombia. Miembro del Grupo de Historia de la Práctica Pedagógica en Colombia. cnoguera@pedagogica.edu.co

3 Becaria del Conselho Nacional de Desenvolvimento Cientifico e Tecnológico, CNPq, Ministério da Ciência eTecnologia de Brasil. Estudiante del programa de posgraduçaõ em Educacão da Universidade Federal do Rio Grande do Sul. dora.marin@ufrgs.br
} 
formas como podemos y debemos actuar para responder a la novedad que cada uno de esos niños y niñas trae consigo, y que escapa a lo que creemos ya saber sobre ellos. Ese conjunto de saberes y de especialidades constituyó, durante el siglo XX, lo que llamamos aquí campo discursivo de la infancia. Este campo de saber, que refleja y a la vez objetiva la infancia como sujeto de conocimiento, es la evidencia y el producto de una preocupación permanente por las formas como los infantes responden y actúan frente a las instituciones y a las prácticas con las cuales tratamos de incorporarlos a la cultura y la sociedad.

El interés de las investigaciones que hemos venido realizando ${ }^{4}$ (origen de este trabajo) no es ampliar este campo discursivo haciendo mejores descripciones, o construyendo más verdades sobre la infancia. La propuesta es de orden diferente: quizás sea hora de guardar silencio, y antes que seguir hablando sobre lo que es, no es o debe ser la infancia, queremos pensar en aquello que se ha dicho y se dice hoy sobre ella. La propuesta consiste en darle una mirada a ese campo que nos ayude a comprender la fascinación por la infancia, fascinación que se refleja en la incesante producción de conocimiento especializado y particularizado sobre las maneras de actuar y pensar de los niños y las niñas, sobre formas diferentes y cada vez más sofisticadas y refinadas de captarlos, acogerlos y domesticarlos. Es hacer la lectura de ese campo discursivo para comprender que con su constitución se producen simultáneamente modos diferentes y contradictorios de ser infante en nuestras sociedades, que reflejan los encantos, desconciertos y temores sentidos cuando vemos que actitudes, prácticas y voluntades atribuidas a los adultos, hoy están presentes en las maneras de ser y vivir de muchos niños y niñas. Es la lectura de esas formas paradójicas de la infancia, pero también de esas formas de apropiación e incorporación que hace cada uno de los niños y las niñas, en sus condiciones y contextos particulares, las que al constituirse en nuevos temas de conocimiento y saber de los especialistas, señalan la novedad y diferencia que comporta esa presencia infantil.

Finalmente, es reconocer en la constitución y ampliación constante del campo discursivo de la infancia -tal como nos enseñó Hannah Arendt- que el nacimiento y los primeros años de vida de una persona son una novedad radical para el mundo humano; es comprender que los niños y las niñas, con sus formas particulares de asirse al mundo sociocultural, son puntos de declive y límite exterior de ese campo que trata de definirlos y atraparlos; es leer en la construcción y movimiento del campo discursivo de la infancia la evidencia y el reflejo de las infinitas novedades y

\footnotetext{
${ }^{4}$ La primera investigación sobre el tema, ya finalizada, fue financiado por el Centro de Investigaciones de la Universidad Pedagógica Nacional, Ciup y la Escuela Normal Superior Nuestra Señora de la Paz, en 2005, titulada "El discurso sobre la infancia en Colombia: Su constitución y transformaciones recientes". La segunda investigación corresponde a la disertación que tiene como título provisional "Além da inocência: Os paradoxos das concepções modernas da infância", adelantado por Dora Marín, en el programa de posgraducão em Educacão da Universidade Federal do Rio Grande do Sul, como Becaria del Conselho Nacional de Desenvolvimento Científico e Tecnológico, CNPq, Ministério da Ciência e Tecnologia de Brasil.
} 
posibilidades que traen para cada generación el nacimiento y los primeros años de vida de un ser humano. Entender la infancia de esta manera es reconocerla como acontecimiento, como figura contradictoria e impredecible, que no puede ni requiere ser definida, delimitada o anticipada, para ajustarla a lo que se sabe y se quiere de ella; es esa infancia figura del porvenir ${ }^{5}$, cuyo encuentro puede procurarse para escucharla y recibirla en su aproximación inquietante, sugestiva y sorpresiva, para quizá reconocer y aprender con ella otras formas de relacionarnos con nosotros mismos, con los otros y con el mundo.

\section{Paradojas de la infancia: entre encantos y desconciertos}

El conjunto de imágenes contradictorias y paradójicas de la infancia, anclado en la concepción que de ella produjo la modernidad experimental, como estudiaremos más adelante, emerge en la relación dinámica de las diversas producciones discursivas sobre la infancia y las prácticas sociales de los sujetos infantiles y acerca de ellos; en otras palabras, en esa particular articulación de la construcción discursiva del mundo social y la construcción social de los discursos sobre la infancia. Visualizar algunas de estas imágenes en torno de aspectos como la criminalidad, la sexualidad, el trabajo y la educación permite, por una parte, percibir los intereses políticos y económicos que están en juego en la disputa por mantener, transformar y controlar una concepción de infancia y, con ella, a los propios niños y niñas; por otra parte, dar una primera mirada a este campo discursivo a través de cuatro oposiciones: infancia en peligroinfancia peligrosa, abuso sexual de menores-erotización del cuerpo infantil, explotación del trabajo infantil-derecho al trabajo, y derechos frente a deberes infantiles.

\section{Infancia en peligro... o infancia peligrosa}

Parece no haber dudas sobre el hecho de que la infancia está en serio peligro. Reuniones internacionales de expertos, denuncias en periódicos y estadísticas gubernamentales así lo testimonian. Además de la pobreza, las enfermedades y la violencia contra los niños y las niñas, especialmente señalados en los países denominados subdesarrollados, nuevos y grandes peligros sobre la infancia aparecen en el escenario social desde mediados del siglo XX; éstos generan menos temor o son menos

\footnotetext{
${ }^{5}$ En palabras de Jorge Larrosa (2000), la figura del porvenir "nombra la relación con el tiempo de un sujeto receptivo, no tanto pasivo como paciente y pasional, de un sujeto que se constituye desde la ignorancia, la impotencia y el abandono, desde un sujeto, en fin, que asume su propia finitud, su propia mortalidad". La figura de la infancia como porvenir es la figura de la novedad y la diferencia, de lo que no puede ser planeado ni previsto, y esa es la principal diferencia con la figura del futuro que "nombra la relación con el tiempo de un sujeto activo definido por su saber, por su poder y por su voluntad, un sujeto que sabe lo que quiere y puede convertirlo en real, un sujeto que quiere mantenerse en el tiempo" (p. 419).
} 
espectaculares. La televisión, primero, y los videojuegos y la Internet, después, son señalados como culpables de ejercer una influencia negativa sobre la infancia: exceso de información, información inadecuada a las particularidades y necesidades de los pequeños receptores; sobreexposición a la violencia y al sexo. Si como resultado del crecimiento de las ciudades tanto educadores como autoridades vieron la calle con bastante recelo, las calles de las grandes ciudades del siglo XXI son una de las mayores fuentes de amenaza, sobre todo para los infantes de las clases medias y altas de la sociedad; para ellos, la calle sólo es un lugar de tránsito obligado que muchos niños y niñas apenas han observado y recorrido a través de las ventanas de buses escolares y automóviles particulares.

Pero a la vez que estos temores sobre la infancia parecen acrecentarse, las frecuentes e insistentes imágenes de los noticieros, periódicos y revistas señalan un aumento de la criminalidad infantil y juvenil. Infantes o jóvenes de distintos sectores sociales -ya no sólo de los suburbios y las zonas marginales de las ciudades- aparecen en el escenario social cometiendo los más diversos crímenes: robos, latrocinios, asesinatos, prostitución, tráfico y consumo de drogas. La infancia parece haber cambiado de víctima a victimaria; estamos frente a la infancia peligrosa, y más allá de la violencia de los infantes de la calle, de los suburbios, ahora los infantes de las clases acomodadas se suman a la escalada de violencia: adolescentes armados que roban para conseguir drogas o simplemente por diversión, muchachos con armas automáticas y de grueso calibre que le disparan a sus compañeros de escuela y universidad. Las imágenes de Columbine, Springfield, Arkansas, Kentucky y las más recientes de Virginia Tech, o las del niño de Río de Janeiro arrastrado por el piso varios kilómetros mientras colgaba del cinturón de seguridad del carro de su mamá, robado minutos antes por unos adolescentes, nos extraen la ternura y la sorpresa se convierte en terror frente a aquellos seres hasta entonces dignos de protección y cuidado.

El éxito de películas como Mi pobre angelito en la década de los noventa muestra que la inocencia y la ingenuidad son trazos que hoy podemos asociar cada vez menos a la infancia. El infante astuto, temerario y perverso es una imagen verosímil, una imagen que no causa molestia. La vivacidad, la precocidad, la hiperactividad y hasta una dosis de petulancia, al contrario de lo que se pensaba hace apenas cincuenta o sesenta años, son trazos de un hijo inteligente y saludable.

\section{Abuso sexual de menores o erotización del cuerpo infantil: la pérdida de la inocencia}

La pedofilia parece haber crecido en las últimas décadas. El abuso sexual infantil es considerado uno de los crímenes más repudiados, pues rompe con aquello que parece más propio de la condición infantil: la inocencia. Privados del secreto del sexo, perdida su ignorancia natural, los niños y las niñas abusados son lanzados de manera violenta al mundo de los adultos. Los noticieros y los periódicos nos sorprenden constantemente con la publicidad de estos casos de abuso a menores (las 
recientes denuncias de sacerdotes pedófilos, en especial de la Iglesia Católica; el caso del ídolo del pop, Michael Jackson, y las denuncias permanentes de grandes redes de tráfico y pornografía infantil, promovidas por la Internet, son apenas una muestra); la propaganda oficial de las instituciones de protección de la infancia alerta sobre el peligro y amenaza constantes a que están expuestos los menores, en particular las niñas: padres, hermanos, familiares y vecinos son posibles agresores, victimarios en potencia, listos a arrebatar la inocencia infantil. Sin el ánimo de subvalorar esta problemática social, valdría la pena preguntarse hasta dónde estas formas de violencia contra la infancia, por una parte, son tan propias de nuestro tiempo, y por otra, han aumentado realmente: ¿estamos frente a un verdadero crecimiento de los casos -en comparación con épocas anteriores-o se trata de una mayor visibilidad de éstos? ¿Qué intereses se benefician y cuáles banderas se fortalecen al evidenciar un incremento en la casuística del maltrato y el abuso infantil? ¿Cuáles y cuántos niños y niñas son beneficiarios reales de las grandes inversiones económicas que se hacen para su cuidado, y de las nuevas normas y legislaciones que buscan protegerlos?

D. Buckingham (2002) señala que tras esas nuevas y crecientes preocupaciones se pueden identificar intereses de distintos grupos de adultos: "Invocar y sentir temor por los infantes es un poderoso recurso para concentrar la atención y el apoyo del público". En otras palabras:

Invocar la figura de la infancia amenazada sirve claramente a los intereses particulares tanto de los grupos militantes como del gobierno. La onda de interés por los malos tratos infantiles, desde los años ochenta, fue favorable a las ambiciones políticas tanto de los grupos evangélicos cristianos como de las feministas, cuya influencia llegó hasta la asistencia social y los organismos de bienestar social (p. 20).

En esta condición, es preciso reconocer que al ser legítimo y necesario pensar en el bienestar y la mejora de las condiciones de vida y seguridad de todos los sujetos sociales, entre ellos también de los niños y las niñas, se deben analizar esas voces de alerta de los medios de comunicación y de las campañas de organismos gubernamentales y ONG, que con la bandera de la protección de la infancia, además de movilizar grandes sumas de dinero, focalizan la atención del público en uno de los síntomas más evidentes, pero no en los problemas sociales, económicos y políticos de los cuales se derivan y que no se están atendiendo; todo esto hace de la infancia una edad de alto riesgo, que lleva a incrementar las medidas de control y la vigilancia sobre niños y niñas, pero también sobre los adultos -como padres, profesores, abuelos, tíos, sacerdotes- que tendrían la responsabilidad social de ofrecer protección permanente. En esa condición de víctimas y victimarios, el temor y la zozobra constante, la desconfianza en los diferentes grupos sociales crece, al tiempo que se aceptan sin mayor discusión políticas de control sobre las poblaciones, limitando sus posibilidades de acción política individual y colectiva.

Este hacer de la infancia una víctima trajo otros problemas. J. Kitzinger (1990) muestra que el enfatizar en la inocencia y en la fragilidad impide percibir y apreciar 
las estrategias construidas por los mismos niños y niñas para evitar o disminuir los efectos que produce el abuso de los adultos. Desde esta perspectiva, la infancia no es inocente, tampoco es cómplice: puede comprender el peligro, entender el significado oculto de algunas propuestas, insinuaciones, gestos, y en muchos casos antes que víctimas pasivas, los infantes construyen opciones que logran obstaculizar las pretensiones de sus agresores. Estos comportamientos son menos conocidos y menos publicitados, quizá porque muestran unos sujetos infantiles activos, que no se acomodan a las ideas de vulnerabilidad, ignorancia e inocencia, y tampoco al lugar de necesidad, protección y cuidado que hemos construido para ellos.

En forma paralela a esta cruzada contra el abuso sexual infantil, presenciamos actualmente una intensa erotización de los cuerpos infantiles, en particular de las niñas. La publicidad de juegos, ropas y golosinas muestra a unas mujercitas, figuras de jóvenes pequeñas cuyos trazos infantiles se han cambiado por actitudes insinuantes, gestos sensuales propios de las modelos de pasarela; el vestido infantil de la niña cada vez se confunde más con las ropas de las jóvenes, usadas también por las mujeres adultas que sueñan con extender la juventud. Escuelas de top models para niñas (y cada vez más para niños) se multiplican, concursos de belleza o de nuevas estrellas son cada vez más comunes. Algunos autores, como J. Felipe y G. Salazar (2003), llaman a este hecho la pedofilización de la sociedad y consideran que "merece ser examinado con mayor atención, en la medida en que los infantes han sido blanco de un fuerte uso comercial, siendo descubiertos como consumidores y, al mismo tiempo, como objetos a ser consumidos". Tenemos aquí un proceso que se opone al iniciado en la modernidad, cuando la infancia no tenía esa connotación sexual y se la separó del mundo de los adultos, donde moraba hasta entonces.

Con excepción de algunos grupos minoritarios, militantes de izquierda, feministas, aunque también conservadores y moralistas, existe hoy una amplia tolerancia a esta forma de explotación del cuerpo infantil: la publicidad parece haber alcanzado un equilibrio entre los sentimientos de ternura e inocencia, por un lado, y sensualidad, por otro. Como si los concursos de belleza, el maquillaje de las niñas y la exhibición de los cuerpos de niños y niñas en los anuncios publicitarios fuesen sólo juguetes y juegos infantiles: a fin de cuentas, es normal que los pequeños jueguen con ser adultos.

\section{¿Explotación del trabajo infantil o derecho al trabajo?}

La lucha contra el trabajo infantil tuvo en la Inglaterra victoriana uno de sus frentes más importantes. En el texto de Cunningham (2002) puede verse la complejidad de esta lucha, que sólo obtuvo consenso social en el siglo XX. Allí estuvieron en juego múltiples intereses: de los infantes y sus familias, de los empresarios, del Estado, pero también de los moralistas y educadores, quienes pretendieron hacerse cargo de los infantes arrebatándoselos a sus familias, con el argumento de su propio beneficio.

Desde esta perspectiva, la problematización del trabajo infantil es un asunto de la modernidad y se constituyó en parte importante del proceso de infantilización de 
niños y niñas, específicamente desde los siglos XVIII y XIX. Hasta antes de dicho periodo los ahora infantes compartían las actividades de los adultos, entre éstas el trabajo, pero la consideración de la infancia como la edad del aprendizaje por excelencia llevó a la separación radical entre la vida infantil y la vida adulta debido a su secuestro en una nueva institución: la escuela pública, hogar de la infancia, como dijeran los pedagogos de la Escuela Nueva a principios del siglo XX. La construcción de la infancia tuvo que ver, entonces, con su aislamiento e implicó una fuerte batalla contra las familias, los dueños de fábricas, lucha que ganó el Estado con la consigna de proteger las tiernas semillas y la educación del futuro de la nación: he ahí la revalorización económica de la infancia, su conversión en el tesoro de la patria, en la fuente de mayor riqueza que un país puede tener.

Así, sectores moralistas de la sociedad utilizaron el aparato estatal, y en particular la escuela, para apropiarse de esa preciosa porción de la población y ponerla al servicio de los intereses de la nación. Después de la Segunda Guerra Mundial, este proceso se intensificó y se extendió globalmente sobre la acción de una organización supranacional, la OIT y su Programa Internacional para la Erradicación del Trabajo Infantil. Pero al tiempo que este programa se divulga y comienza a funcionar en distintos países, otro tipo de organizaciones y movimientos, las llamadas Asociaciones de Niños y Adolescentes Trabajadores, amparadas en la defensa de los derechos de la infancia -promulgados por otra organización supranacional, la Unicef-, se constituyen para exigir el derecho al trabajo. Según estas asociaciones, la OIT estaría violando la Convención Internacional sobre los Derechos del Niño, pues allí se establece que los niños y niñas tienen derecho a la libertad de pensamiento, conciencia y religión (art. 14), así como a la libertad de asociación (art. 15).

Esta discusión hace evidente la tensión y la lucha que implica la definición de una concepción de infancia: elaborada por la OIT y la Unicef, sin participación activa y decisiva de los directos implicados, y otra, la puesta en escena por estos movimientos conformados por niños, niñas y adolescentes. La primera, como es lógico, propone una infancia que precisa cuidado y protección -cosa que estas organizaciones supranacionales están listas para ofrecer-, concepción que se pretende universal, válida para todos los niños y niñas de las diferentes culturas. La otra se trata de una infancia que tiene voz, que decide, que escoge, pero también de una forma de ser infancia en unas condiciones particulares de pobreza, marginación y opciones limitadas, maneras de ser que no se acomodan a las imágenes de los expertos internacionales, pero que están presentes en muchas culturas, sobre todo en las llamadas tercermundistas.

\section{Los derechos del niño... ¿y dónde están los deberes?}

Existe hoy un indiscutible consenso sobre la defensa de los derechos de la infancia: se trata de un avance, un paso fundamental -dicen los impulsores- de la sociedad, de la democracia, de la civilización. Con este reconocimiento se pretende proteger 
a quienes permanecieron sometidos durante mucho tiempo a las arbitrariedades de los adultos, quienes estuvieron como enmudecidos y alienados, víctimas de los malos tratos y de las elecciones erróneas de los padres, profesores y tutores. Este discurso, cada vez más común, consecuencia de su publicidad, de su difusión permanente por múltiples agencias sociales, gubernamentales y particulares, choca contra prácticas cotidianas en las cuales es preciso contar con la obediencia de los infantes: actividades familiares, tareas escolares, ocupaciones que suponen la existencia de deberes que hay que asumir. Ciertamente, el discurso de los derechos veló los deberes; en algún sentido, se podría decir que casi borró y desapareció el asunto de los deberes de la infancia. Philippe Meirieu (2000) destaca este hecho cuando cuestiona el discurso de los derechos de la infancia, pues, según él, la infancia no es un ser acabado, por lo que no es posible otorgarle los mismos derechos de un adulto maduro. En realidad, para este pedagogo

Los derechos de la infancia son simplemente los deberes educativos de los adultos y aquello que anuncia la Convención sobre los Derechos del Niño es en alguna forma, o nivel de la exigencia en el cual nosotros, los adultos, debemos intentar mantenernos (p. 156).

En términos pedagógicos, este autor muestra la contradicción existente entre la proclamación de la libertad y la autonomía de la infancia, y la forma como se supone que tales facultades aparecen en la infancia: ¿se trata del resultado de la educación, de la acción pedagógica, o ellas son algo así como facultades que por efecto del desarrollo o el crecimiento aparecen en un momento determinado? Sobre este punto, Meirieu sostiene que reconocer la existencia de los derechos de la infancia es, en primer lugar, afirmar la existencia de los infantes de carne y hueso, de sus pasiones e ilusiones, de sus sumisiones y rebeldías. En segundo término, aseverar que si los niños y niñas no son seres acabados - ¿acaso existen seres acabados? - tampoco son seres completos. Entonces, habría que escribir -como hicieron quienes redactaron la Convención sobre los Derechos del Niño- no que la infancia tiene derecho a la libertad de expresión, pero sí que, dado que la infancia se expresa desde su nacimiento no sólo a través de la voz y la palabra, tiene derecho a ser escuchada, no el derecho a ser aprobada sistemáticamente, pero sí sistemáticamente el derecho a ser escuchada y su corolario esencial: el derecho a ser contradicha. Sin duda alguna, las cosas habrián sido así mucho más claras. Tampoco que la infancia tiene derecho a la asociación, mejor reconocer que los niños y las niñas, en cualquier lugar, se reúnen en grupos y bandos, y que tienen derecho a recibir una educación que con seguridad les permita escapar del dominio de sus jefes; así no habría que hablar tanto de la libertad de conciencia y religión, y en su lugar se podría reconocer que los niños, las niñas y los adolescentes se proponen interrogantes sobre el sentido de su existencia y que tienen derecho a ser considerados seriamente, también en este campo (pp. 156-157).

Estas nuevas formas de leer los derechos de la infancia nos permiten observar cómo esos discursos tan actuales dejan por fuera asuntos de orden pedagógico 
trascendentales, al tiempo que cuestionan la propia idea de infancia que los sustentan. Como diría Meirieu, la exaltación de los derechos de la infancia tiende a reducir la importancia de sus deberes en cuanto sujeto en formación, limitando la acción pedagógica e ignorando sus posibilidades en la construcción de la libertad y la autonomía.

Tales paradojas infantiles permiten observar la forma compleja, tensa y contradictoria como se articulan el conjunto de saberes y conocimientos sobre la infancia, y las prácticas sociales de los sujetos infantiles y sobre ellos, señalando las particulares condiciones históricas del siglo XX, en especial de las últimas tres décadas, que propiciaron la producción del campo discursivo sobre la infancia. Una segunda mirada a este campo, pero ahora desde el acercamiento a los discursos sobre la infancia -aquellos que hablan de la imposibilidad de continuar inscribiendo a los niños y las niñas de hoy en esta categoría- nos permiten reconocer que es en la tensión entre las diferentes formas de objetivar al sujeto infantil, propuesto por los saberes y disciplinas -el sujeto del crecimiento y el desarrollo de la psicología, el sujeto del aprendizaje de la pedagogía, el sujeto del cuidado y la higiene de la medicina, la semilla social de la sociología, etc.- y no en su reunión o acuerdo, donde se producen y ajustan las prácticas sociales sobre niños y niñas, y que es en esa tensión de saberes, prácticas e instituciones donde se produce la figura quimérica de la infancia, aquella criatura hecha con partes de otros seres -cabeza de adulto, cuerpo de niño, actitud de joven-, ensamble asustador, monstruoso, inquietante que nos causa, al mismo tiempo, fascinación y temor.

\section{La infancia hoy: producción de un campo discursivo}

La concepción de obediencia, inocencia y fragilidad que la modernidad promovió (la literatura moralizante diseñó y la escuela, principalmente, intentó formar) está alterada hoy por una imagen que es como su lado oscuro, su otra cara cruda, ruda: se trata de otra infancia, experta, vivaz, maliciosa, y hasta salvaje, bárbara y peligrosa. Las preguntas de los niños y las niñas ya no son tan inocentes, detrás de ellas se revela información, raciocinio, y algunas veces hasta sagacidad; los gestos de sumisión, fragilidad, dependencia, que identificaran a la infancia educada, quedaron en los recuerdos de los años de nuestros abuelos; ahora la precocidad, la vivacidad, la hiperactividad y algo de insolencia, se consideran características propias de la niñez contemporánea. A pesar de conocer de la existencia de infancia delincuente desde hace mucho tiempo, hoy parece, ante la opinión pública, que el fenómeno de la infancia criminosa va en aumento y que constituye una verdadera amenaza para la sociedad. ¿Qué aconteció? ¿Qué produjo tales transformaciones entre las maneras de ser infante de abuelos y nietos?

En las conversaciones cotidianas de las familias, de los profesores, de los amigos, se explican estos cambios como efectos de transformaciones en los propios niños y niñas: "Los niños de hoy no son como los de antes", dicen; "Alguna cosa 
cambió en ellos”, "Ya no son más como eran”, "Hoy son más inteligentes”. Entre los especialistas, psicólogos, sociólogos, pedagogos y culturalistas, esas mutaciones se explican como efecto de los grandes cambios socioculturales acontecidos en el siglo $\mathrm{XX}$, sobre todo con aquellos asociados a los desarrollos tecnológicos y de las comunicaciones, y que ofrecen a los niños y a las niñas nuevas oportunidades para su acelerado desarrollo, llevando también a modificaciones en la actitud educativa de los padres, haciéndolos más tolerantes y conscientes de las necesidades de sus hijos. Se trataría, desde esta perspectiva, del efecto normal del proceso evolutivo de la sociedad moderna.

Reconocidos investigadores, como el sociólogo norteamericano N. Postman (1982), el primero en anunciar la muerte de la infancia en su libro titulado La desaparición de la infancia; los argentinos M. Narodowski (1999), en Después de clase; Corea y Lewcowicz (1999), en ¿Se acabó la infancia? Ensayo sobre la destitución de la niñez, y el brasileño J. Ghiraldelli (2000) en As Concepções de Infância e as Teorias Educacionais Modernas e Contemporâneas, desarrollan esta idea para el caso latinoamericano. Los citados autores consideran que no se trata de una simple transformación sino de un acontecimiento de amplias dimensiones: la propia muerte de la infancia moderna. Según ellos, en cuanto la infancia es una construcción social, no es una figura eterna; entonces, puede desaparecer por efectos de ciertos cambios sociales y culturales que no tienen que ver con la idea de progreso, de desarrollo o de evolución. Retomando los análisis del historiador francés Philippe Ariès (1978), que había mostrado en los años sesenta cómo se fue construyendo el moderno sentimiento de la infancia en Europa a partir del siglo XVII, estos autores intentan argumentar la crisis, la decadencia y las dificultades de esa concepción moderna para dar cuenta de las condiciones contemporáneas de la niñez. En tal sentido, el desaparecimiento de la infancia es la constitución de un nuevo sujeto o de una nueva forma de subjetivación que se aparta de lo que significó este concepto para la sociedad occidental.

Otros autores, como el inglés Buckingham (2002), se oponen a las tesis de Postman, y aunque reconocen que la infancia es una construcción social, sus análisis muestran la permanencia de esta categoría aún ubicada, en la sociedad contemporánea, sobre intensas presiones producto de las múltiples, aceleradas e intensas transformaciones de las últimas décadas. En particular, el trabajo, las llamadas industrias culturales, cine, televisión, radio, videojuegos, Internet y música, lo desarrollan Kincheloe y Steinberg (2000) en su libro Cultura infantil y multinacionales, en el que señalan que estos artefactos culturales serian los responsables por los cambios radicales en las formas de ser, de comportarse, consumir, hablar, pensar y desear de la infancia. Hay entonces, en opinión de estos autores, una cultura infantil creada por las corporaciones multinacionales en su afán por buscar y conquistar nuevos consumidores, cultura basada en los intereses del mercado y en una ideología sexista, racista y discriminatoria. Los sujetos infantiles, al constituirse en blanco privilegiado de estas corporaciones, son sometidos, explotados y manipulados, utilizando para 
ello la noción de inocencia en favor de intereses meramente comerciales, como se puede ver con claridad en el estudio de Giroux (2003), quien señala cómo la promoción de concursos de belleza, la producción masiva de juguetes, películas, y muchos otros productos aparentemente inocentes, están permeados por fuertes contenidos ideológicos.

Asistimos así a una intensa problematización de la infancia en la sociedad contemporánea. Desde la opinión pública y los medios de comunicación, pasando por las diversas instituciones gubernamentales, las ONG, las agencias de cooperación internacional, hasta los círculos académicos, es posible encontrar numerosos estudios, proyectos, investigaciones, planes, programas, campañas alrededor del problema de la infancia o de la infancia como problema. Se puede decir que nos encontramos frente a un campo discursivo, entendiendo por esto una región -históricamente delimitada- de saberes y disciplinas de distintas procedencias y niveles de elaboración diferenciados, que se cruzan, oponen, luchan desde nociones, conceptos, métodos y teorías particulares, por la definición, delimitación o determinación de un objeto o de unos objetos particulares de saber (y de poder).

El trabajo de dar cuenta de la constitución de ese campo discursivo, aunque interesante y necesario, sobrepasa las posibilidades de este texto; se trata, por el momento, de una mirada inicial que nos permitirá explorar las condiciones de emergencia de esa figura ambigua y paradójica, capaz de generar al mismo tiempo ternura y miedo, protección y rechazo.

Así las cosas, la producción del campo discursivo sobre la infancia es la producción de la infancia como objeto de saber, que ocurre en el marco de una serie compleja de relaciones e interacciones entre discursos provenientes de sistemas discursivos de diferentes niveles. Ese campo discursivo es un espacio abierto, donde se localizan discursos de órdenes y niveles diferentes: discursos de las disciplinas que hacen de la infancia su objeto de conocimiento (psicología infantil, pediatría, trabajo social, pedagogía, etc.), y discursos de los saberes sobre la infancia, cuya sistematicidad es menor y su delimitación y precisión conceptual difusa. Este último grupo es ese conjunto de saberes producto de las experiencias, de las prácticas transmitidas como saber popular (de los viejos a los jóvenes) y que pueden ser el resultado de la apropiación que los sujetos sociales hacen de las informaciones que les vienen de disciplinas científicas, por medio de dos vías: los expertos en el cuidado y la atención de la infancia (médicos, profesores, trabajadores sociales, psicólogos infantiles) y los medios de comunicación (programas de televisión, radio, revistas, libros de autoayuda, etc.).

Esta metáfora de campo y las dos primeras miradas que de él hemos intentado -las figuras paradójicas y los discursos contemporáneos sobre la insuficiencia de la categoría para albergar a los niños y las niñas contemporáneos- nos permiten señalar varios aspectos: en primer lugar, el complejo tejido de relaciones a través de las cuales la infancia como objeto de conocimiento y de saber se instala en nuestra cultura oc- 
cidental, cómo ella se moviliza y tensiona en el entretejido de los sistemas discursivos que se han creado, instituyendo un conjunto de prácticas y saberes que producen las subjetividades de niños y niñas. En segundo término, cómo los sujetos infantiles son producidos en un conjunto de reglas y normas particulares y con base en patrones institucionales específicos, que siempre resultan insuficientes para atraparlos, someterlos y definirlos. Y finalmente, la producción y emergencia de otras posiciones de sujeto en ese campo discursivo: los adultos, que en el papel de padres, madres, profesores o expertos, son producidos y contribuyen a la producción de ese sujeto infantil.

\section{Una mirada histórica a la producción discursiva de la infancia}

Esta tercera aproximación al campo discursivo de la infancia es una aproximación a su constitución histórica, al momento en el que consideramos -siguiendo algunos autores- emergió la concepción de infancia sobre la cual se fundamentan nuestras ideas contemporáneas acerca de la existencia de una naturaleza infantil. Para empezar, es necesario hacer una aclaración: la modernidad no inventó sólo una concepción de infancia; desde el siglo XVII, es posible identificar, por lo menos, dos formas distintas de concebir aquello que llamamos infancia: una primera, que denominamos infancia clásica, es aquella cuyo descubrimiento anuncia Ariès (1978) en su conocido libro sobre La infancia y la vida familiar en el Antiguo Régimen, y otra, la infancia romántica -por su énfasis en el individuo, la libertad y la subjetividad-, esa cuyo primer bosquejo hiciera Rousseau en su Emilio. La primera está asociada a las ideas de obediencia, educabilidad y disciplina; la segunda a los de inocencia, interés y aprendizaje. Una corresponde a la época de las disciplinas, de la didáctica, y la otra al momento de la regulación, de la pedagogía como ciencia.

En este último sentido, y de manera rápida, pues no es propósito de este texto profundizar en el asunto, la distinción se sustenta en la siguiente diferencia entre didáctica y pedagogía: la primera emerge en los siglos XVI y XVII -Comenio sería su punto más sistemático-: la segunda, relacionada pero claramente diferenciada, aparece en la segunda mitad del siglo XVIII con Rousseau y Kant, y sólo a finales del siglo XIX, en las versiones alemana, francófona y anglosajona, traspasaría su umbral epistemológico ${ }^{6}$.

\section{La infancia clásica}

Esta infancia es aquella que aparece en la interrelación entre prácticas de escolarización de la Reforma y la Contrarreforma; instauración de espacios de encierro (instituciones de secuestro) como los hospicios, escuelas, talleres; surgimiento de sujetos especialistas en la enseñanza y la educación de los niños, primero, y sólo un tiempo

\footnotetext{
${ }^{6}$ Sobre estas tres tradiciones ver los aportes de Echeverri (2003).
} 
después, de las niñas; destitución de los espacios tradicionales de socialización de los niños y las niñas de las sociedades premodernas, como sostienen Varela y Álvarez-Uría (1991). Se trata de un nuevo sujeto cuya principal característica es la maleabilidad, su posibilidad de ser formado, su educabilidad. Cuando Comenio (1994) decía que era conveniente formar al hombre para que llegara a ser tal, establecía a la educación como la condición para adquirir de manera plena la humanidad. No se nace propiamente humano, se llega a serlo. El infante es una semilla que es preciso cultivar, pero a diferencia de otras criaturas, no basta su desarrollo natural, requiere un injerto:

... la condición del hombre y de la planta son semejantes. Pues así como un árbol frutal... puede desarrollarse por sí mismo, pero silvestre y dando frutos silvestres también; es necesario que si ha de dar frutos agradables y dulces sea plantado, regado y podado por un experto agricultor. De igual modo el hombre se desarrolla por sí mismo en su figura humana (como todo bruto en la suya); pero no puede llegar a ser animal racional, sabio, honesto y piadoso sin la previa plantación de los injertos de sabiduría, honestidad y piedad (p. 24).

Así, la enseñanza es aquella acción a través de la cual el maestro (agricultor) injerta, metódicamente (con método), tales cualidades en la pequeña planta infantil con el propósito de apoyar el desarrollo del hombre que está como en potencia en el niño. En este orden de ideas, la didáctica, la gran didáctica -la Didáctica Magna- es el sistema mediante el cual se produce esa humanidad. Sólo ella, en cuanto disciplina, puede disciplinar tanto el cuerpo infantil como los saberes; en tal sentido, se entiende la disciplina como disciplina cuerpo y disciplina saber, según los desarrollos de VeigaNeto (1996). Es por medio de la enseñanza, y gracias al método y a la escuela, que se forma al hombre a partir del sujeto infantil incompleto y dependiente. La escuela no fue, entonces, el lugar de acogida de la infancia, pero sí su lugar de constitución: la escolarización de los niños generó un proceso de infantilización operado a través del disciplinamiento exhaustivo. La literatura histórica tradicional había confundido este problema, como señala Postman (1982) a propósito de J. H. Plumb:

En sus escritos sobre los años de formación del concepto de infante, J. H. Plumb (1971) observó que "el niño se convirtió cada vez más en objeto de respeto, una criatura especial, de naturaleza diferente y con necesidades diferentes, que debía ser separado y protegido del mundo adulto" (p. 9)... pero el señor Plumb tiene puesto todo al revés. Los niños no eran separados de la otra población porque se creyera que tenían una naturaleza diferente y necesidades diferentes. Se creía que tenían naturaleza diferente y necesidades diferentes porque estaban separados de la otra población. Y estaban separados porque se había vuelto esencial que aprendieran a leer y escribir y se comportaran como miembros de una cultura de la imprenta (p. 15).

De este modo, e inicialmente en las clases altas de la sociedad, se fue encarnando una infancia dócil, moldeable, disciplinable y por tanto, obediente y sometida.

Como dicen Varela y Álvarez-Uría (1991) refiriéndose a las características de esa infancia: 
... maleabilidad, de donde se deriva su capacidad para ser modelada; debilidad (más tarde inmadurez) que justifica su tutela; rudeza, siendo entonces precisa su "civilización"; flaqueza de juicio, que exige desarrollar la razón, cualidad del alma, que distingue al hombre de las bestias; y, en fin, naturaleza en la que se asientan los gérmenes de los vicios y de las virtudes -en caso de moralistas más severos, se convierte en la naturaleza inclinada al mal- que debe, en el mejor de los casos, ser encauzada y disciplinada (p. 19).

En la medida en que la escuela logró diseminar por el territorio social esa primera concepción moderna de infancia, ésta se fue consolidando hasta llegar a ser aceptada como natural por la mayoría de la población a principios del siglo XX. Es preciso, sin embargo, tomar algunas precauciones en este punto, pues, por un lado, la aceptación de una supuesta naturaleza infantil implicó una larga lucha entre diversos sectores sociales por el control de esa nueva porción de la sociedad; gobierno, familias, y dueños de fábricas y talleres, se disputaron la tutela de los niños y las niñas, su educación y su utilización en función de sus intereses particulares. Por otro lado, la naturalización de esta concepción de infancia fue un proceso irregular y lento, que empezó en las clases aristocráticas y tuvo como blanco primero a los niños, y sólo en los siglos XIX y XX, alcanzó a las niñas y otros sectores de la población, pero siempre dejando por fuera una porción menor que, por no haberse institucionalizado, quedó fuera de su alcance.

\section{La infancia romántica}

Rousseau introdujo una diferencia central frente a la concepción de infancia clásica: ya no se trata de la planta infantil que requiere injertos; la razón -sabiduría, honestidad, piedad- no es algo que se pueda insertar dentro del niño, es el resultado del proceso de desarrollo cuya condición es la propia acción del sujeto, su interacción con el medio, con el mundo, con la naturaleza y con los otros hombres. La infancia de Rousseau no se tiene que enseñar, ella misma debe aprender, debe conocer las cosas, la verdad, lo correcto -el bien y el mal- como producto de su actividad, como resultado de su manera de reactuar. La educación negativa de Rousseau es la condición para pasar de la didáctica a la pedagogía: de la enseñanza como disciplinamiento a la enseñanza como regulación. En términos de Caruso (2006):

La enseñanza como disciplinamiento había analizado y reorganizado el espacio, el tiempo, y las formas de actividad de la sala de clase para poder ordenar y gobernar a estos "otros". Por el contrario, la enseñanza como situación de regulación tenía que gobernar estos sujetos en crecimiento, que ya no eran vistos meramente como una masa puesta a disposición para que se le diera "forma" y formación a través de la aplicación cotidiana de las disciplinas (pp. 58-59).

Pero Rousseau es como el primer trazo, la primera muestra de esa nueva concepción de infancia que sólo encuentra su figura completa entre finales del siglo XIX y principios del siglo XX en los trabajos de los llamados pedagogos activos. Pestalozzi y Fröebel no se separaron completamente de la concepción clásica de infancia; 
por su parte, Herbart, con su pedagogía científica basada en una nueva psicología -que se aparta de la clásica psicología de las facultades del alma-, y una nueva filosofía práctica, puso el interés como problema clave en la nueva pedagogía. Este concepto, que se desarrollará en otra dirección, a partir de la biología y del darwinismo, por Claparède y Decroly, pero también en otro sentido por Dewey, permitirá instalar la regulación en el corazón de las prácticas pedagógicas. Siguiendo a Caruso (2006), la regulación es una técnica específica de la biopolítica ${ }^{7}$, y la enseñanza reguladora será su versión pedagógica. Distanciándose de las prácticas disciplinarias y de la didáctica, y sustentándose en las elaboraciones de la nueva ciencia biológica, la regulación constituyó una ruptura frente al saber y a las prácticas pedagógicas de la modernidad clásica, ruptura que podría caracterizarse como una "intervención ligada al Estado -y ya no meramente a las instituciones- y vinculada a la preocupación por optimizar la administración de los procesos vitales de la población” (p. 60).

Es a través del concepto de interés que la regulación aparece en la nueva pedagogía. Este acontecimiento podría entenderse como un proceso de economía de la enseñanza, o sea, el ahorro de la actividad de enseñanza en función de la autoactividad del aprendiz, del infante. Como diría Dewey (1936):

Esta oposición fundamental entre el niño y el programa, presentada por estas dos teorías, puede ser reproducida en otra serie de términos. Disciplina es la consigna de los que exaltan el programa escolar; interés, la de los que colocan al niño como blasón en su bandera. El punto de partida de los primeros es lógico; el de los segundos, psicológico. Los primeros defienden la necesidad de una preparación y formación adecuada de los maestros; los segundos, la necesidad de simpatía para con los niños y el conocimiento de sus instintos naturales. "Guía y control" son las contraseñas de una escuela; "libertad e iniciativa”, la de la otra. Allí se proclama la ley; aquí la espontaneidad. Los unos aman lo viejo, la conservación de lo que se ha logrado con el trabajo y esfuerzo de los siglos; los otros prefieren lo nuevo, el cambio, el progreso (p. 32).

La historia de las ideas pedagógicas ha confundido la regulación o la autorregulación con la idea de autonomía o libertad, pero aquí se trata sólo de una nueva forma de ejercicio de poder sobre los sujetos infantiles; no cualquier forma, ciertamente, sino una muy sofisticada estrategia biopolítica que se podría definir como economía política del yo: al sujeto (infante) ya no lo coaccionan más desde el exterior (el maestro a través de la enseñanza), sino que lo gobiernan desde el interior (él mismo), mediante procesos de autocoacción. Para eso, el sujeto requiere un aparato psíquico particular, donde la voluntad es comprometida, ya no como una facultad del alma, sino como una capacidad que el propio sujeto desarrolla en

\footnotetext{
7 "Así, 'regulación' puede definirse como un haz de acciones operativas y procesos de simbolización en un patrón de 'buen' orden de carácter orgánico y cuyo objetivo es fomentar y dirigir al mismo tiempo los procesos de crecimiento. Por ello, la regulación tiene que respetar la autorregulación de ese proceso -lo que sucede en los distintos campos de aplicación de la biopolítica-, pero no por ello renunciar a darle al mismo una dirección determinada y, con ello, a gobernarlo" (p. 58).
} 
su proceso de crecimiento y maduración. Para Ferrière, esta nueva voluntad es una energía, una potencia, un impulso, una fuerza que opera en el individuo más allá de su conciencia:

Él no lo sabe aún, pero siente que la alegría y la felicidad están asociadas a la energía más grande, a la que no se deja dominar por los acontecimientos, sino que los domina; no lo sabe todavía, pero siente también que esta liberación de su energía creadora tiene como característica, sobre todo, la posesión de sí mismo. ¿Y qué significa poseerse sin haber dominado las múltiples tendencias que surgen en él, los caprichos, antojos y fantasías de todo género? (p. 37).

Sobre esta fórmula de economía se pensó la acción pedagógica mediante la cual fue posible construir ese aparato psíquico requerido para la posesión de sí mismo. En esta dirección, la llamada educación nueva fue menos la liberación del sujeto infantil para desdoblar su naturaleza, que la propia construcción de esa naturaleza infantil. Así las cosas, la insistencia rousseauniana de establecer una particularidad para la infancia y la defensa que la Escuela Activa hizo de un interés natural espontáneo en los niños y niñas comprometieron la definición de esa naturaleza infantil que constituyó a los infantes en objetos de saber, al tiempo que propició una economía de la enseñanza en la que el control de los niños se garantizaba, ya no actuando directamente sobre ellos, sino sobre los ambientes de aprendizaje que se producían en función de introducir al niño en el mundo adulto, el universo del orden, del lenguaje, de la ley.

Así pues, durante el siglo XX la definición de los límites entre el mundo infantil y el mundo adulto se encuentra profundamente marcada por la tensión entre el proceso de naturalización del interés y la inocencia en los sujetos infantiles que la Escuela Activa movilizó -y que podemos reconocer en esta mirada histórica del campo-y los intereses económicos y políticos de gobiernos, multinacionales y medios masivos de información y comunicación, que pueden reconocerse en la revisión hecha sobre las figuras paradójicas y los discursos contemporáneos sobre la desaparición o transformación de la infancia.

\section{La quimera infantil contemporánea: hacia el reconocimiento de una in-fancia}

La palabra quimera puede tener dos acepciones: en un primer sentido, podría referirse a una ilusión, una fantasía, una utopía. Pero eso implicaría partir de la existencia de un ideal de infancia, de un modelo por alcanzar. Así pues, no pretendemos realizar una comparación entre una concepción elaborada por los teóricos -psicólogos, pedagogos, por ejemplo-, y una realidad, la infancia materialmente existente. Como hemos señalado hasta ahora, nos estamos refiriendo a una concepción de infancia que, como cualquier otra concepción, es producto de unas prácticas y a su vez produce unas prácticas, en este caso, prácticas de escolarización, higienización, medicalización, por ejemplo, prácticas en las cuales se ha formado y construido aquello que denominamos niñez. 
En su segundo sentido, quimera hace referencia a un monstruo fabuloso con cabeza de león, cuerpo de cabra y cola de dragón; en otro, más general, a una ilusión, una fantasía, una utopía. En el primer sentido, la infancia de hoy es como aquella criatura hecha con partes de otros seres, de otras criaturas, un ensamble -ciertamente monstruoso y claramente asustador, inquietante y asombroso, como nos dejan ver las paradojas y las tensiones que dan forma a ese sujeto infantil en la época contemporánea- estructurado en un campo donde discursos, prácticas e intereses de distinto orden y procedencia luchan por in-formar, definir, delimitar eso que llamamos infancia. Contrario a las condiciones de constitución de esta infancia contemporánea, la infancia que hemos denominado clásica se produjo en un panorama completamente diferente, sus condiciones de emergencia y de consolidación fueron otras; ella no la constituyeron saberes y prácticas de tantos órdenes, tan diversos y opuestos entre sí: la didáctica, la psicología de las facultades del alma, por una parte, y las prácticas disciplinarias, la evangelización, la escolarización, por otra, convergieron entre los siglos XVI y XVIII, constituyendo esa forma de ser infantil, forma que, según hemos señalado, no se difundió en todas las clases sociales ni siguió los mismos pasos de unas a otras, tal como lo señalaran también Varela y Álvarez-Uría (1991).

Podríamos decir, si se quiere, en términos de los debates contemporáneos, que si hubo una infancia que desapareció, esa fue la infancia clásica. Ahora bien, con la emergencia, surgimiento y consolidación -entre finales del siglo XVIII y principios del siglo XX- de la que hemos denominado infancia romántica se inició la configuración de ese campo discursivo acerca de la infancia, en cuyo paisaje se produjeron prácticas contradictorias sobre los cuerpos infantiles, prácticas que trataron de responder tanto a los intereses económicos, políticos y sociales de cada momento -que se evidencian en las tres miradas al campo que hicimos en los apartados anteriores-, como a las novedades, inquietudes y diferencias que proponen esos niños y niñas en sus formas particulares de recibir e incorporar el mundo y la cultura.

En estos términos, reconocer esa quimera infantil contemporánea, esa criatura formada en un territorio de disputa y permanente movimiento de saberes, disciplinas, prácticas e instituciones, es observar que el intento de contener, conocer, dominar e introducir a niños y niñas en nuestras comprensiones, en nuestras razones, en nuestros saberes, emergen esas figuras infantiles que, al mismo tiempo y de una sola vez, poseen cabeza de adulto, cuerpo de niño y apariencia de joven. Tenemos hoy -un poco como fue antes de la modernidad- unos adultos en cuerpos pequeños, seres más o menos autorregulados, sujetos de derechos que deciden sobre sus vidas -como nosotros los adultos, en un marco restrictivo de ofertas sociales y culturales-, que piensan, razonan; sujetos de saber -que explican, dan razones, argumentan-que cometen crímenes, compran, consumen, pero también unos pequeños, con cuerpos en crecimiento -frágiles, débiles-, que necesitan cuidado y protección, aunque vistan, se alimenten y, en general, consuman las mismas cosas que jóvenes y adultos. 
Esta quimera es ese ser que se incorpora, que se encarna en los niños y las niñas con los que vivimos; es ese infante paradójico -que puede estar en peligro y ser peligroso; ser un explotado por tener que trabajar, o un sujeto social que exige su derecho al trabajo para sobrevivir en un mundo cada vez más estrecho en oportunidades; una víctima sexual o un modelo cuyo cuerpo erotizado hace crecer el mercado de productos, revistas, programas de televisión, entre otros; un sujeto de derechos que puede incluso denunciar el exceso de autoridad de sus padres- que crece casi sin compromisos para con él mismo y para con los otros. Es también lo que queda de esa infancia clásica, en especial de los vestigios de la obediencia, la que hay que someter, pero que por su fragilidad requiere cuidado. En fin, es esa criatura que lentamente se fue constituyendo e incorporando en los niños y las niñas con los cuales convivimos hoy.

Una quimera es un monstruo, ciertamente. $Y$ un monstruo es algo terrible porque hiere nuestra sensibilidad, en este caso, nuestra sensibilidad moderna. En tal sentido, el monstruo es "una producción contra el orden regular de la naturaleza", según nos lo recuerda la Real Academia Española de la Lengua; pero también una cosa excesivamente grande o extraordinaria. La infancia es, en verdad, una producción contra natura, y si in-fancia hace referencia a ausencia de palabra, eso infantil hoy, a pesar de todo lo que se hable sobre ello, tiene aún mucho de inefable: las dudas y temores que nos producen los sujetos infantiles están relacionados con aquello que huye de nuestro control, de nuestros saberes, de nuestro lenguaje; con aquello que aún no podemos nombrar cómodamente, decir, capturar porque se nos escapa, porque es impronunciable; es esa in-fancia que nos acontece, que es contradicción.

La ampliación permanente del campo discursivo de la infancia y el reconocimiento de la presencia de esa quimera infantil con la cual convivimos se constituyen, finalmente, en las evidencias más claras para pensar la infancia como problema; esto es, la ausencia de palabras para nombrar y delimitar al sujeto infantil de hoy, pero también la insuficiencia e imposibilidad para controlar, prever y atrapar esas diferencias, esas formas siempre distintas con las cuales cada nuevo ser humano se apropia e incorpora en una cultura. Así las cosas, más que pensar la infancia como problema, se trata de considerar el problema de la in-fancia, del encuentro con ese otro que está por venir, de ese otro que no cabe en nuestras palabras ni en nuestras explicaciones. Es reconocer que para el encuentro con esos nuevos seres humanos es preciso olvidar las definiciones y delimitaciones que hemos producido de ese mundo infantil, y dejar las pretensiones de producir y anticipar esos lugares de sujeción, de identificación con los cuales procuramos anclarlos a nuestra cultura. Se trata, por el contrario, de salir al encuentro de esas novedades de esas diferencias, para quizá pensar de nuevo en aprender otras cosas, nuevas y diversas formas de estar en el mundo y de establecer relaciones con los otros. 


\section{Bibliografía}

Ariès, P. (1978). História Social da criança e da família. Rio de Janerio: Zahar.

Buckinham, D. (2002). Crecer en la era de los medios electrónicos. Madrid: Morata-Fundación Paideia.

Caruso, M. (2006). La biopolítica en las aulas. Prácticas de conducción en las escuelas elementales del Reino de Baviera, Alemania (1869-1919). Buenos Aires: Prometeo.

Comenio, J. A. (1994). Didáctica Magna. México: Porrúa.

Cunningham, H. (1994). Trabajo y explotación infantil. Situación en la Inglaterra de los siglos XVII al XX. Madrid: Ministerio de Trabajo y Seguridad Social.

Dewey, J. (1936). El niño y el programa escolar. Madrid: Losada.

Felipe, J. y Salazar, B. (2003).

"Erotização dos corpos infantis na sociedade de consumo". Pro-Posições, 3 (14), 119-129.

ECHEverri, A. (2003). El lugar de la Pedagogía dentro de las Ciencias de la Educación. En: Pedagogía y Epistemología (pp. 127-184). Bogotá: Coop- erativa Editorial Magisterio-Grupo de Historia de la Práctica Pedagógica.

Girardelli, P. (2000). As Concepções de Infância e as Teorias Educacionais Modernas e Contemporâneas. En: Revista Educación y Realidad, 25 (1), 45-48.

Giroux, H. (2003). La inocencia robada. Madrid: Morata.

Kincheloe, J. L. y Steinberg, R. (2000). Cultura infantil y multinacionales. Madrid: Morata.

KitZinger, J. (1990). ¿Who are you kidding? Children, power and the struggle against sexual abuse. En: A. James y A. Prout (Eds.) Constructing and reconstructing childhood: contemporany issues in the sociological study of childhood. (pp. 34-62). London: Routledge Falmer.

Larrosa, J. (1998). Pedagogía Profana. Porto Alegre: Contrabando.

Meirieu, P. y Develay, M. (2000). Emilio regresa pronto... ellos se volvieron locos. Bogotá: mimeo.

Varela, J. y Álvarez-Uría, F. (1991). Arqueología de la escuela. Madrid: La Piqueta. 
Veiga-Neto, A. (1996). A ordem das disciplinas. Tese de Doutorado, Programa de Pos-Graduação em Educação, Faculdade de Educação, UFRGS, Porto Alegre, Brasil.
Zuluaga, O. et ál. (2003). Pedagogía y Epistemología. Bogotá: Cooperativa Editorial Magisterio-Grupo de Historia de la Práctica Pedagógica. 